JAllit

\title{
An Exploratory Study on the Constraints for Entrepreneurial Activity: A Case of Micro and Small Enterprises in Kano, Nigeria
}

\author{
Abubakar S. Garba, Universiti Malaysia Sarawak \\ Shazali Abu Mansor, Universiti Malaysia Sarawak \\ Fariastuti Djafar, Universiti Malaysia Sarawak
}

\section{Executive Summary}

This paper explores the challenges confronting Nigerians, particularly women in entrepreneurial activity. The paper uses a qualitative approach to obtain the necessary information from micro and small entrepreneurs. In-depth interviews were conducted to collect data from 25 key informants who own micro and small enterprises that have been in operation for at least five years. The qualitative data was transcribed and presented in a narrative manner. The paper found liquidity constraints to be the most serious problem as most of the entrepreneurs cannot access microfinance from government agencies or microfinance institutions. It is also discovered that the participation of women in entrepreneurship is lower in comparison to their male counterparts. The existing microfinance policy should be revisited to ascertain loopholes that render the policy less effective. Close supervision of the microfinance institutions is needed to ensure compliance to ethical standards and practices in the issuance of credit and loans. To make more generalizable conclusions, similar studies are needed in Nigerian states where the participation of women is low.

\section{Introduction}

Entrepreneurial activity is a sine qua non for private sector development and imperative for a country's economic prosperity. It is very difficult to separate micro and small business enterprises from entrepreneurial activity because they are the vehicle for entrepreneurial development. Their importance in economic development has been recognized throughout the world in terms of creativity, innovativeness and competitiveness. The micro, small and medium enterprises (MSMEs) create jobs, provide nurturing ground for domestic entrepreneurial capacities and innovativeness and managerial competencies for private sector development. MSMEs play a prominent role in developing countries that are characterized by high levels of unemployment and poverty.

Kano state in Nigeria is particularly endowed with abundant human and material resources that can be used to build a strong, virile and prosperous economy. It is often called the center of Nigerian commerce because of its long history of entrepreneurial activity. There are a high number of family businesses and self-employment among the youth and adult population in the Kano state. Unfortunately, most of the micro and small entrepreneurs in the state do not make a significant impact in driving economic development through innovativeness and 